\title{
Maria, Ida e Dorací: acidentes de trabalho das mulheres nas minas de carvão de Criciúma/SC (Brasil) na década de 1940
}

\section{Bruno Mandelli (*)}

${ }^{*}$ ) orcid.org/0000-0003-3584-1806. Máster en Historia Cultural por la Universidad Federal de Santa Catarina (UFSC) y Estudiante de doctorado en la Universidad Federal de Rio Grande do Sul (UFRGS). bruno.o.mandelli@gmail.com.

SUMARIO: 1.-Introdução e aporte teórico-metodológico. 2.-A legislação de acidentes de trabalho no Brasil. 3.-Os acidentes de Dorací Pereira e de Ida Paulina. 4.-O trabalho das mulheres e os acidentes do ponto de vista médico. 5.- Trabalhadoras na Justiça, uma análise dos processos de Acidentes de Trabalho. 6.- Reflexões finais.

RESUMO: Este artigo analisa os acidentes de trabalho envolvendo mulheres que trabalharam na mineração de carvão no município de Criciúma, localizado no estado de Santa Catarina, Brasil, na década de 1940. A partir dos processos de Justiça, é problematizado como os acidentes impactavam a vida dessas trabalhadoras, afetando suas atividades de trabalho dentro e fora dos espaços de produção. Além de refletir sobre um aspecto pouco estudado pela literatura, este artigo também faz um balanço quantitativo dos processos envolvendo mulheres trabalhadoras, a fim de analisar quais são os resultados alcançados pelos mesmos.

PALAVRAS-CHAVE: Brasil, trabalhadoras, acidentes de trabalho, mineração de carvão, processos da Justiça.

KEYWORDS: Brazil, workers, accidents at work, coal mining, court proceedings. 


\section{Introdução e aporte teórico-metodológico}

Viver a trabalhar nas minas de carvão de Santa Catarina, não era uma tarefa fácil em meados do século XX. Especialmente para as mulheres, que além das jornadas de trabalho exaustivas na «escolha» de carvão ${ }^{1}$, chegavam em casa e tinham o trabalho doméstico como parte da dupla jornada de trabalho.

Este artigo analisará, através do processo de acidente de trabalho de três operárias, como eram as relações de produção nas minas de carvão de Criciúma, como esse tipo de trabalho afetava a saúde dessas mulheres (devido aos constantes acidentes laborais), qual a opinião médica sobre o trabalho feminino naquele contexto, e como a Justiça constituía-se como um espaço importante de luta pelos seus direitos negados pelas empresas mineradoras.

O marco teórico do artigo insere-se na História Social do Trabalho, que têm problematizado nas últimas décadas a relação entre experiências de mobilização dos trabalhadores e sua relação com o Direito e as leis ${ }^{2}$. Sobre este aspecto, a noção de Direito e de Lei foram problematizadas a partir das obras de E. P. Thompson. O autor possui uma definição dialética: a) compreende a Lei como expressão do domínio de uma classe sobre outra, como «mediação das relações de classe com um conjunto de regras e sanções adequadas, as quais, em última instância, confirmam e consolidam o poder da classe existente» ${ }^{3}$; b) como um espaço não de consenso, mas de conflito, onde entram em confronto interesses opostos e, muitas vezes, contraditórios $^{4}$; c) que no curso das batalhas no campo da Lei, os dominados podem obter vitórias parciais, isto é, nem sempre saem como perdedores, e que nessas «pequenas» vitórias, pode-se impor uma restrição ao «arbítrio dos dominantes» ${ }^{5}$, isto é, elas retroagem sobre o próprio domínio da Lei ${ }^{6}$.

Sobre a metodologia de análise das fontes judiciais, os processos de acidentes de trabalho, são contendas em que a trabalhadora relata ter sofrido determinado acidente durante o seu trabalho e exige o pagamento de uma

\footnotetext{
1. A escolha era chamado o processo de separação manual da pedra de carvão, que era feito pelas mulheres, daí serem chamadas pela comunidade em que viviam como «escolhedeiras».

2. Ver Silva, Fernando Teixeira da. Trabalhadores nos Tribunais: Conflitos e Justiça do Trabalho em São Paulo no Contexto do Golpe de 1964. São Paulo: Alameda; 2016.

3. Thompson, Edward. Senhores e Caçadores: a origem da lei negra. Rio de Janeiro: Paz e Terra, 1987, p. 350.

4. Thompson, n. 3, p. 351.

5. Thompson, n. 3, p. 356.

6. Thompson, n. 3, p. 356.
} 
indenização pela lesão sofrida. Nesse sentido, que muitas vezes, as trabalhadoras encontram-se diante de uma situação em que precisam defender seu direito à indenização, quer seja pecuniária, médica, farmacêutica ou hospitalar, para poder garantir a sua sobrevivência. E a narrativa que constroem para exigirem a aplicação de um direito, pode nos dizer algo sobre como percebiam a sua condição de trabalho e de vida. Estamos de acordo, neste ponto com E. P. Thompson, de que «as relações de classe eram expressas, não de qualquer maneira que se quisesse, mas através das formas da lei» ${ }^{7}$.

Além disso, estamos de acordo com a necessidade de se considerar as pesquisas sobre as mulheres não como um campo separado, mas inserido na própria História, «e que considerar a experiência das trabalhadoras pode alterar a narrativa central sobre a História do Feminismo» ${ }^{8}$.

Dialogando com a historiografia, propõe-se neste artigo esmiuçar uma problemática sobre a agência dessas mulheres nas suas lutas por direitos, em um âmbito que até o momento não foi problematizado pela historiografia: a partir dos acidentes de trabalho e das doenças profissionais, procura-se questionar como agiram na defesa de seus direitos, em última instância sobre a defesa da sua capacidade de trabalho, e qual a relação que essa luta por direitos fazia relação com a legislação de acidentes de trabalho em vigor no Brasil desde 1919.

\section{A legislação de acidentes de trabalho no Brasil}

No Brasil, as primeiras décadas do século XX foram fortes as mobilizações e greves operárias que passaram a impulsionar e pressionar os parlamentares para que fossem criados direitos que beneficiassem os trabalhadores e lhes garantisse alguma proteção social. Estes possuíam como pauta de reivindicações uma lista que abarcava, entre outras, a jornada de 8 horas, aposentadoria, a regulamentação do trabalho da mulher, o direito a férias bem como seguro contra acidentes ${ }^{9}$. Isso porque as condições de trabalho,

\footnotetext{
7. Thompson, n. 3, p. 356.

8. Fraccaro, Glaucia Cristina Candian. Uma história social do feminismo: diálogos de um campo político brasileiro (1917-1937). Estudos Históricos (Rio de Janeiro) [artigo na Internet]. 2018 [citado 15 Out 2018]; 31 (63): 7-26. Disponível em: https://dx.doi.org/10.1590/s2178-14942018000100002

9. Ferraz, Eduardo Luís Leite. Acidentados e Remediados: a lei de acidentes no trabalho na Piracicaba da Primeira República (1919-1930). Revista Mundos do Trabalho [artigo na Internet]. 2010 [citado 15 Out 2018]; 2 (3): 207. Disponível em: http://dx.doi.org/10.5007/1984-9222.2010v2n3p206
} 
em geral, eram muito precárias em todo país no começo do século XX, com jornadas quase sempre superiores a dez horas, além do trabalho de menores em várias funções perigosas, «somavam-se à insalubridade do ambiente para formar um quadro de mortes e acidentes constantes» ${ }^{10}$.

O projeto de lei sobre acidentes de trabalho, que fora apresentado pelo senador paulista Adolfo Gordo em 1915, «foi particularmente bem recebido pelo Centro Industrial Brasileiro (...) declarando-se este prontamente favorável à adoção de regulamentação específica sobre um dos mais espinhosos problemas sociais da indústria moderna» ${ }^{11}$.

Porém, mesmo com o interesse de setores empresariais na apresentação de um projeto que pudesse lhes garantir um controle sobre as situações imprevisíveis no âmbito laboral, como de acidentes e doenças profissionais, não fossem as pressões internas - do movimento operário em suas pautas pela redução da jornada de trabalho e melhoria das condições de trabalho, seguro contra acidentes - e as externas - com o fim da Primeira Guerra em 1919 e o Tratado de Versalhes no qual o Brasil foi signatário que efetivou a criação da Organização Internacional do Trabalho (OIT), que entre outras medidas, recomendava o reconhecimento dos novos direitos sociais como a já mencionada redução da jornada de trabalho para oito horas diárias e máximo quarenta e oito semanais. Nesse contexto, muitos países da América Latina passaram a incorporar uma legislação sobre os acidentes de trabalho, influenciados pela conjuntura mundial: Guatemala (1906), em El Salvador (1911), Peru (1911), Argentina (1915), Colômbia (1915), Venezuela (1915), Cuba (1916), Chile (1916), Panamá (1916), México (1917), Brasil (1919), Uruguai (1920), Equador (1921), Bolívia (1924), Costa Rica (1925) ${ }^{12}$.

Em virtude dessa conjuntura mundial e nacional, em 1918 surgiu a primeira legislação que regulamentou os acidentes de trabalho no Brasil foi criada no ano de 1919, através do Decreto n. ${ }^{\circ} 3.724$ de 15 de janeiro de 1919, regulamentado posteriormente pelo Decreto n. ${ }^{\circ} 13.498$ de 12 de março de 1919, constituindo-se, portanto, a primeira lei brasileira que adotou a

10. Mattos, Marcelo Badaró. Trabalhadores e Sindicatos no Brasil. São Paulo: Expressão Popular; 2009, p. 42.

11. Ferraz, n. 9, p. 207.

12. Gallo, Óscar. Acidentes de trabalho na Colômbia. Doutrina, lei e jurisprudência (1915-1950). Revista Mundos do Trabalho [artigo na Internet]. 2015 [citado 15 Out 2018]; 7 (13): 131. Disponível em: http://dx.doi.org/10.5007/1984-9222.2015v7n13p129. 
«teoria do risco profissional», que teve como criador Félix Faure em $1883^{13}$. Esta jurisprudência conhecida também pela teoria do «fato do trabalho» implicava na responsabilização do empregador a pagar uma indenização ao operário «quando o acidente ocorresse "pelo fato do trabalho ou durante este. $\mathrm{O}$ acidente era visto como uma espécie de fato natural e próprio da atividade laborativa» ${ }^{14}$. Todavia, a definição de acidente de trabalho era bastante restrita, pois incluía tão somente as «moléstias» adquiridas pelo exercício do trabalho, o que desconsiderava as doenças causadas pelas condições degradantes do mesmo ${ }^{15}$. Desse modo, estavam fora de proteção os casos de acidentes em que fosse constatado casos de força maior ou dolo da própria vítima, o que proporcionava brechas para que o empresariado pudesse contestar o pagamento das indenizações.

Segundo Anna Beatriz de Sá Almeida, essa lei foi criticada na época por juristas e especialistas que a denunciavam pelo fato dela não conter dispositivos relacionados à questão preventiva dos acidentes de trabalho. Como exemplo, cita o médico Afrânio Peixoto, que em estudo publicado em 1926, faz uma análise da lei de 1919 e uma crítica pela mesma tratar exclusivamente das «moléstias exclusivas do exercício do trabalho» ${ }^{16}$.

Durante a primeira República, novas estruturas estatais foram sendo criadas para acompanhar a necessidade de institucionalização das crescentes demandas trabalhistas em curso. O decreto n. 16.027 de 30 de abril de 1923 criou o Conselho Nacional do Trabalho (CNT), subordinado ao Ministério da Agricultura, Indústria e Comércio, sendo composto por doze membros dos quais oito representantes do governo, dois patrões e dois trabalhadores, todos escolhidos pelo presidente da República ${ }^{17}$. Este conselho teria por função de ser um órgão consultivo para assessorar o governo federal em matéria trabalhista. No mesmo ano de 1923 também foi criado o Departamento Nacional de Saúde Pública (DNSP), que contava na proposta aprovada pela

13. Aravanis, Evangelia. Um olhar sobre os Processos de Acidentes de Trabalho no Rio Grande do Sul (1934-1950). Aedos [artigo na Internet]. 2009 [citado 15 Out 2018]; 2 (4): 31. Disponível em: https://seer.ufrgs.br/aedos/article/view/10625.

14. Ferraz, n. 9, p. 215.

15. Almeida, Anna Beatriz de Sá. As doenças 'do trabalho' no Brasil no contexto das políticas públicas voltadas ao trabalhador (1920-1950). Revista Mundos do Trabalho [artigo na Internet]. 2015 [citado 15 Out 2018]; 7 (13): 75.

Disponível em: http://dx.doi.org/10.5007/1984-9222.2015v7n13p65.

16. Almeida, n. 15, p. 75.

17. Gomes, Ângela de Castro; Silva, Fernando Teixeira da. A Justiça do Trabalho e sua História: os direitos dos trabalhadores no Brasil. Campinas: Editora Unicamp; 2012, p. 17. 
Câmara dos Deputados, com «a atividade de polícia sanitária das fábricas e oficinas» e a instituição da Inspetoria de Higiene Industrial e Profissional ${ }^{18}$.

Porém, sem dúvida, foi com a criação do Ministério do Trabalho, Indústria e Comércio (MTIC) em 1930, quando da instauração do novo governo da revolução de 1930, que se o Estado deu um passo significativo na formulação de políticas sociais mais incisivas para mediar os conflitos do mundo do trabalho, dentre eles, a questão acidentária. Cabia ao MTIC, por exemplo, a organização da relação das doenças consideradas profissionais, baseando-se para isso, nas indicações da Organização Internacional do Trabalho ${ }^{19}$.

Em 10 julho de 1934, durante o governo provisório de Getúlio Vargas, foi promulgado o Decreto n. ${ }^{\circ}$ 24.637, a segunda Lei de Acidentes de Trabalho, que além de manter a «teoria do risco profissional» ou do «fato do trabalho» como fundamento, obrigou no seu artigo 36, que empregadores oferecessem a garantia de seguro contra acidentes de trabalho. Esse artigo representou um aprimoramento na legislação, haja vista que a partir de então os trabalhadores passam a contar, em teoria, com um seguro em caso de acidente. Surgiu assim o que a doutrina denominou de autoseguro.

Esse seguro deveria ser pago pelo empregador em instituição particular, ou em depósito nos bancos públicos, ou em título da dívida pública federal. O fato é que na ampla maioria dos casos, pelo menos no segmento de carvão mineral em Santa Catarina, eram contratadas seguradoras particulares para prestarem esse serviço, muitas vezes companhias seguradoras estrangeiras que atuavam com filiais no Brasil.

Além disso, foi ampliado a definição de doença profissional, uma vez que em seu art. 1, a lei estabelecia que enfermidades inerentes ou peculiares a certas atividades também estavam encampadas na denominação «doenças profissionais»:

«\$ $1^{\circ}$ São doenças profissionais, para os efeitos da presente lei, além das inerentes ou peculiares a determinados ramos de atividade, as resultantes exclusivamente do exercício do trabalho, as resultantes exclusivamente especiais ou excepcionais em que o mesmo for realizado, não sendo assim consideradas as endêmicas quando por elas forem atingidos empregados habitantes da região» ${ }^{20}$.

\footnotetext{
18. Almeida, n. 15, p. 68

19. Almeida, n. 15, p. 76.

20. Legislação Informatizada —Decreto n. ${ }^{\circ} 24.637$, de 10 de Julho de 1934-Publicação Original [citada 15 Out 2018].
} 
Desse modo, pelo menos na letra da lei, começou a ser possível para os trabalhadores reivindicarem uma indenização pelas condições especiais ou excepcionais do trabalho, o que incluía um rol de doenças causadas pelo trabalho direto com substâncias como chumbo, fósforo, sílica, entre outras ${ }^{21}$.

Durante o Estado Novo de Getúlio Vargas (1937-1945), a legislação acidentária passou por uma nova mudança: foi a Reforma da Lei de Acidentes de Trabalho, promulgada pelo Decreto 7.036 de 10 de novembro de 1944 . Dentre os destaques importantes desse Decreto, está a ampliação em seu $1 .^{\circ}$ artigo do conceito de infortúnio laboral, que equipara o acidente à doença resultante das condições de trabalho; além disso, uma relação direta dessa ampliação do que engloba o acidente de trabalho, está a admissão da teoria «concausa», que retirou do conceito de acidente de trabalho a causa única e exclusiva existente na legislação anterior.

$\mathrm{Na}$ legislação de acidentes de 1934 (Decreto n. ${ }^{\circ} 24.637$ ) afirmava em seu art. $1 \$ 1$ que era doenças profissionais as resultantes «exclusivamente do exercício do trabalho»; no Decreto-lei n. ${ }^{\circ} 7.036$ - a «reforma da Lei de Acidentes de trabalho»- essa exclusividade anterior é retirada. Por sua vez, é adotado no art. 1 da nova lei as palavras «direta ou indiretamente» resultantes das condições de trabalho.

Além dessa ampliação, o estabelecimento da distinção entre doenças profissionais inerentes a determinadas categorias profissionais, além de doenças resultantes das condições especiais ou excepcionais em que o trabalho é realizado; e a introdução de um sistema de manutenção do salário para os casos de incapacidade permanente ou morte do trabalhador.

Portanto, o Decreto 7.036 buscava claramente reparar e prevenir os infortúnios de forma mais ampla possível, fato que abrigava várias reivindicações dos trabalhadores do final dos anos 1930 e início dos de 1940. Essa legislação representou uma sistematização de amplos aspectos de temas relacionados ao mundo do trabalho e os inscreveu de forma normativa.

Em geral, sobre as Leis de Acidentes abordadas neste artigo, é possível perceber uma ampliação cada vez maior da interferência estatal nos conflitos entre capital e trabalho, de modo a dirimir as questões acidentárias e minimizar os efeitos negativos sobre a saúde dos trabalhadores no que tangia aos infortúnios laborais. Se a primeira lei de 1919 atribuía o acidente como

Disponível em: http://www2.camara.leg.br/legin/fed/decret/1930-1939/decreto-24637-10-julho1934-505781-publicacaooriginal-1-pe.html.

21. Almeida, n. 15, p. 76 . 
causa única no exercício do trabalho, «exceto nos casos de força maior ou dolo da própria vítima», a reforma da Lei de Acidentes de 1944 ampliou de forma significativa esse conceito, abrangendo aqueles acidentes produzidos «direta ou indiretamente, lesão corporal, perturbação funcional, ou doença», além do seu art. 3 que considerava caracterizado o acidente «ainda quando não seja êle a causa única e exclusiva da morte ou da perda ou redução da capacidade do empregado» 22 .

\section{Os acidentes de Dorací Pereira e de Ida Paulina}

Um acidente de trabalho ocorrido no dia 18 de setembro de 1945, às 13 horas, na Companhia Carbonífera Catarinense, município de Criciúma, impediu que a operária Dorací Pereira continuasse seu trabalho, que havia começado às 06 horas daquele dia. A «escolhedeira» de 17 anos, transportava uma «padiola» cheia de carvão para a caixa de embarque, quando deixou-a cair sobre seus pés, o que lhe ocasionou como ferimento «uma pisadura no pé esquerdo» ${ }^{23}$.

Dorací ficou sem trabalhar por algum tempo, mas em face de não receber as diárias a que teria direito de acordo com a Lei de Acidentes de Trabalho ${ }^{24}$, resolveu entrar com uma ação contra a mineradora e sua seguradora de acidentes, a Brasil Companhia de Seguros. O salário da depoente era de CR\$ 10,00 (dez cruzeiros) por dia de trabalho, com uma jornada de 8 horas, que começava às $06 \mathrm{~h}$ e terminava às $15 \mathrm{~h}$, com intervalo de 1 hora para o almoço. A jornada de trabalho lhe exigia dedicação semanal, de segunda a sábado. No seu depoimento ao promotor público, Dorací relata que já havia sofrido

22. Legislação Informatizada —Decreto-Lei n.o 7.036, de 10 de Novembro de 1944-Publicação Original [citada 15 Out 2018].

Disponível em: http://www2.camara.leg.br/legin/fed/declei/1940-1949/decreto-lei-7036-10novembro-1944-389493-publicacaooriginal-1-pe.html -.

23. Acervo Acidentes de Trabalho. Processo 101A00179. Localizado em: CEDOC, Centro de Memória e Documentação da UNESC, caixa 04.

24. Em 10 de novembro de 1944, durante a ditadura do Estado Novo, Getúlio Vargas promulgou uma «Reforma da Lei de Acidentes de Trabalho», através do Decreto n. 7.036 , regulamentado pelo Decreto n. 18.809 de 1945. Dentre os destaques importantes desse Decreto, está a ampliação em seu $1 .^{\circ}$ artigo do conceito de infortúnio laboral, que equipara o acidente à doença resultante das condições de trabalho; além disso, uma relação direta dessa ampliação do acidente de trabalho, está a admissão da teoria «concausa», que retirou do conceito de acidente de trabalho a causa única e exclusiva existente na legislação anterior. 
outro acidente, «que foi ocasionado por uma pancada com a padiola em um dedo», e «que não esteve recolhida em nenhum hospital», além de «nunca ter contraído doença profissional» ${ }^{25}$.

O Juiz da Comarca de Criciúma, Euclydes de Cerqueira Cintra, expediu um mandado ao oficial de justiça para convocar a acidentada e os representantes da companhia mineradora para deporem em audiência no dia 16 de fevereiro de 1946, no Fórum da Comarca, no centro da cidade. Em posse do exame médico pericial, o Juiz concluiu pela condenação da seguradora e o pagamento de uma indenização no valor de CR\$ 1.596,40.

Esse processo judicial de acidente de trabalho foi um dos doze processos envolvendo mulheres que trabalhavam na mineração no município de Criciúma, entre os anos de 1943 e 1950. Essas mulheres faziam a escolha do carvão, isto é, realizavam a separação manual da pedra do carvão da pirita, parte inutilizável que vinha incrustada no minério durante seu processo de extração do subsolo.

O trabalho feminino e infantil foi de suma importância para o crescimento da mineração em Santa Catarina. Além do trabalho no subsolo e galerias, executado pelos homens, existia o trabalho na parte terrestre da mina. O livro de Carlos Renato Carola sobre o trabalho feminino na mineração, Dos subterrâneos da História: as trabalhadoras das minas de carvão de Santa Catarina (1937-1964), foi um marco que mostrou como o trabalho feminino e infantil foi fundamental para o crescimento da mineração no período. O autor reconstrói, através de depoimentos de ex-trabalhadoras, as chamadas «escolhedeiras», memórias que marcam a presença feminina no trabalho do carvão, esquecida pela historiografia tradicional:

«A principal atividade feminina, nas minas, era a seleção ou escolha manual do carvão, daí serem conhecidas popularmente como 'escolhedeiras' ou 'catadoras' de carvão. Considerava-se o trabalho na escolha como sendo uma atividade tipicamente feminina» ${ }^{26}$.

O pesquisador demonstrou que o trabalho na escolha era uma tarefa considerada pelos proprietários das minas como «leve» por sua natureza repetitiva de separar a pedra de carvão da pirita, que era o rejeito. Em jor-

25. Acervo Acidentes de Trabalho. Processo 101A00179. Localizado em: CEDOC, Centro de Memória e Documentação da UNESC, caixa 04.

26. Carola, Carlos Renato. Dos subterrâneos da história: as trabalhadoras das minas de carvão de Santa Catarina (1937-1964). Florianópolis: Editora da UFSC; 2002, p. 26. 
nadas de trabalho de oito horas diárias, elas trabalhavam com uma picareta para realizar a separação do carvão, que depois era colocado em caixas ou «padiolas»; estes, por sua vez, quando estavam carregados, eram levados para serem despejados em uma caixa de embarque do carvão ${ }^{27}$.

E assim como os homens que trabalhavam no subsolo eram suscetíveis a acidentes devido a natureza exploratória e mal organizada do trabalho, também as escolhedeiras de carvão sofriam com acidentes e doenças relacionadas ao trabalho, uma vez que não existiam nenhuma preocupação por parte das companhias mineradoras relacionada a segurança do trabalho, seja na parte terrestre, ou no interior das galerias.

Outro processo de acidente de trabalho foi da operária Ida Paulina. No dia 19 de abril de 1948, na escolha de carvão da Companhia Brasileira Carbonífera de Araranguá (CBCA), Ida Paulina sofreu um acidente: cortou-se na palma da mão direita com a picareta que manuseava para o trabalho. A escolhedeira tinha 22 anos e era viúva, possuía instrução primária (sabia ler e escrever) e recebia um ordenado de CR $\$ 12,00$ por dia de trabalho ${ }^{28}$.

Em virtude da empregadora CBCA negar-lhe «os cuidados médicos que merece, tampouco indenização» ${ }^{29}$, a operária recorreu ao Curador de Acidentes a fim de fazer valer seus direitos previstos na legislação. $\mathrm{O}$ Curador de Acidentes e Promotor Público Moacyr de Oliveira (acumulava a dupla função) emitiu um of ício ao Juiz de Direito da Comarca de Criciúma, intimando a empregadora e sua seguradora de acidentes, a Lloyd Industrial Sul Americano.

O perito médico Manif Zacharias, examinou a operária e concluiu em seu laudo médico que a operária, «em consequência de acidente no trabalho, foi cortada 2 vezes na palma da mão direita, tendo recebido alta sem estar estabelecida». E que em função do acidente sofrido, resultou em «hipertrofia e hiperfunção dos dedos mínimos e anular da mão direita», não podendo readquirir sua capacidade de trabalho «por se tratar de lesão de caráter permanente».

Em virtude do laudo médico, o Juiz de Direito David do Amaral Camargo propôs um acordo para o pagamento da indenização: o pagamento de CR\$

\footnotetext{
27. Carola, n. 26, p. 28.

28. Acervo Acidentes de Trabalho. Processo 101A00358. Localizado em: CEDOC, Centro de Memória e Documentação da UNESC, caixa 08.

29. Acervo Acidentes de Trabalho. Processo 101A00358. Localizado em: CEDOC, Centro de Memória e Documentação da UNESC, caixa 08.
} 
1.587,60 pela seguradora Lloyd Industrial devido «à imobilidade em extensão do dedo anular da mão principal». Tal valor foi pago e quitado na data de 28 de setembro de 1948.

\section{O trabalho das mulheres e os acidentes do ponto de vista médico}

Um contemporâneo que evidenciou o trabalho feminino na mineração foi o médico do Departamento Nacional de Produção Mineral (DNPM) Francisco de Paula Boa Nova Jr., que trabalhou na região carbonífera de Santa Catarina entre 1944 e 1952, quando escreveu um relatório para o DNPM intitulado Problemas médico-sociais da indústria carbonifera sul-catarinense (1953), que consiste em um minucioso relatório sobre as condições de vida e de saúde daquela população.

Em um capítulo específico sobre as mulheres, Boa Nova Jr. afirma que a média de idade das mulheres era de 16 a 25 anos, o que de fato, coincide com as os processos de acidentes de trabalho pesquisados. Em jornadas de trabalho de $8 \mathrm{~h}$ de segunda a sábado, as mulheres trabalhavam em locais insalubres, sem qualquer equipamento de proteção individual contra acidentes, como botinas para proteger-lhes pés e pernas. O autor (médico) narra que:

«É serviço que, não requerendo esforço físico exagerado, apresenta apenas o risco frequente dos ferimentos a que estão sujeitas essas mulheres nos pés e no terço inferior das pernas, devido a que, trabalhando a maioria descalça, ao pisarem nos pequenos montes de carvão ou material refugado que jazem em derredor dos locais de trabalho, se ferem e se cortam constantemente» ${ }^{30}$.

O fato de ser um serviço que não exigia esforço físico «exagerado», como menciona o médico é questionável, pois as padiolas de carvão podiam chegar a pesar $30 \mathrm{~kg}$. Talvez, comparado com o serviço dos vagoneteiros que tinham que empurrar carros de até $1.000 \mathrm{~kg}$ em trilhos de madeira em uma rampa inclinada, fosse considerado menos «pesado»; mas tal critério não pode ser atribuído como forma de classificação do trabalho, uma vez que as mulheres possuíam diversos outros trabalhos além da escolha, e mesmo na escolha, possuíam jornadas de trabalho de 8 horas diárias.

30. Nova Jr., Francisco de Paula Boa. Problemas médico-sociais da indústria carbonífera catarinense. Rio de Janeiro: Departamento de Fomento da Produção Mineral; 1953, p 55. 
A seguir, serão apresentadas algumas fotografias do trabalho das «escolhedeiras» nas minas de carvão, porém, antes, é preciso salientar que a fotografia, como um documento, retrata um momento do passado, mas que não pode ser considerado como verdade ou prova, mas como marca ou «índice», isto é, como «um tipo de signo que se define como vestígio do objeto que lá esteve - o referente» ${ }^{31}$.

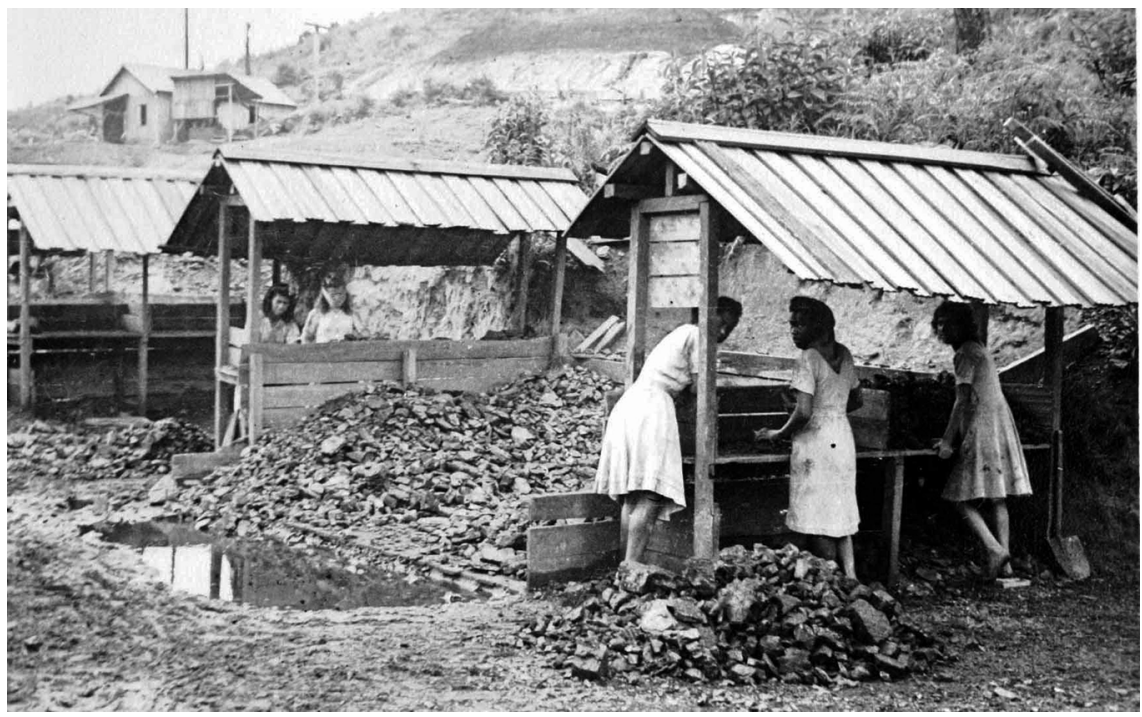

Imagem 1. Mulheres «escolhedeiras» fazendo o trabalho da escolha do carvão em uma mina de carvão de Criciúma na década de 1940. Foto sem local exato. Fonte: Acervo CEDOC, Centro de Memória e Documentação da UNESC

$\mathrm{Na}$ foto acima podemos ver as mulheres fazendo a escolha do carvão, com uma picareta à mão, que batiam contra a pedra de carvão para separá-la da pirita. Nota-se que elas trabalhavam descalças. De um ponto de vista dos riscos de acidentes e doenças profissionais as «escolhedeiras» estavam sujeitas a perigos tal como os homens, pois o trabalho com a picareta lhes provocava os acidentes relatados acima. Ferimentos e, consequentemente, infecções eram constantes.

31. Lima, Solange Ferraz de; Carvalho, Vânia Carneiro de. Fotografias: Usos sociais e historiográficos. In: Pinsky, Carla Bassanezi; De Luca, Tania Regina, orgs. O Historiador e suas fontes. São Paulo: Contexto; 2013, p. 42. 
O médico Boa Nova Jr., afirmou no relatório que as escolhedeiras eram reconhecidas fora dos locais de trabalho pelas suas «cicatrizes que apresentam nas pernas ou mesmo por ferimentos recentes, alguns extensos, que as obrigam, às vezes, a se valerem do 'encosto' no seguro quando tais ferimentos se infectam, ocasionando a interrupção de seu trabalho por vários dias» ${ }^{32}$.

$\mathrm{O}$ «encosto» a que o médico pejorativamente se refere às escolhedeiras acidentadas, era o seguro médico, regido pelo Decreto 7.036/44, que obrigava o pagamento das despesas médicas, hospitalares e de diárias pelo tempo parado em função do acidente sofrido.

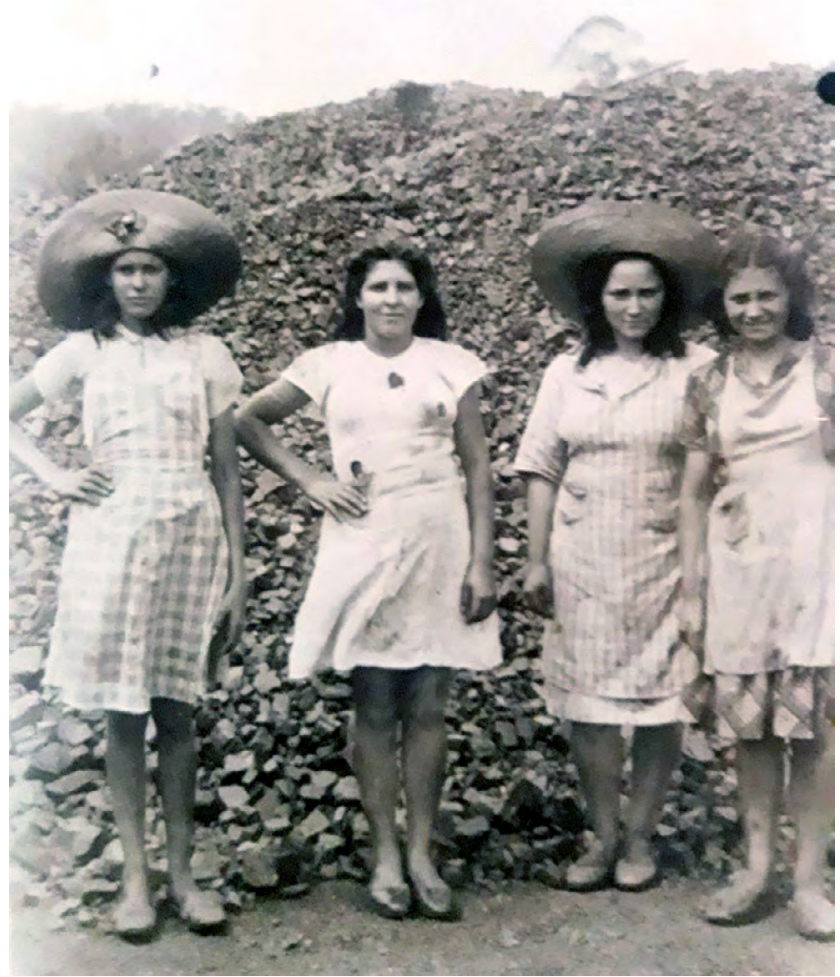

Imagem 2. Fotografia de 8 de novembro de 1941, sem local exato. Da esquerda para direita: Maria Ceniria, F. Poncinha, Rosinha. Fonte: Acervo Arquivo Histórico Municipal Pedro Milanez.

32. Nova Jr., n. 30, p. 55. 
$\mathrm{Na}$ foto acima pode-se perceber quatro mulheres «escolhedeiras» do carvão, que trabalhavam na mina União. As duas mulheres dos cantos deve-riam ser mais jovens, com aproximadamente entre 14 e 18 anos de idade. As mulheres do centro da foto um pouco mais velhas, deveriam ter entre 20 e 30 anos de idade. O mais importante de se observar, talvez, seja a postura delas na foto, de «firmeza» e altivez, que refletem a função que desempenhavam na mineração, que exigia grande esforço físico assim como dos homens.

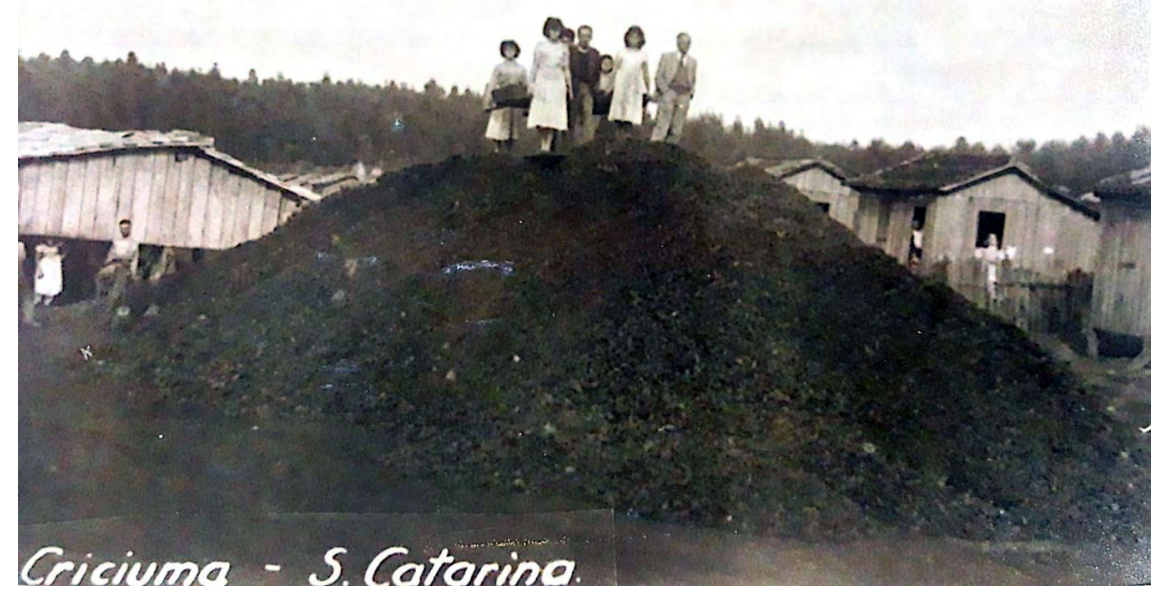

Imagem 3. Fotografia da década de 1940 sem identificação de local. Fonte: Acervo Arquivo Histórico Municipal Pedro Milanez.

Nesta outra fotografia acima aparecem mulheres, homens e crianças em cima de um monte de carvão, que eram depositados aos montes próximos às minas e às Vilas Operárias. A mulher à esquerda dos demais está carregando uma caixa, aparentemente uma "padiola», onde eram carregadas as pedras de carvão que escolhiam. Nota-se ao fundo da foto ao lado direito também casas de madeira, enfileiradas e separadas por uma pequena cerca. E do outro lado, ao fundo, um galpão que deveria ser utilizado para escolha. Um outro fator que pesquisamos foi sobre a forma de pagamento dos salários das escolhedeiras, este era de acordo com sua produtividade, tal como os mineiros e ajudantes no subsolo, mas além da quantidade de «caixotes» ou 
«padiolas» escolhidas, era de acordo também com a quantidade de horas trabalhadas no mês.

Pudemos constatar isso através do processo de acidente de trabalho da «escolhedeira» Maria Stephano, que trabalhou na Companhia Carbonífera Metropolitana S.A, e que acidentou-se em 14 de abril de 1946. A trabalhadora havia caído quando transportava a «padiola» para a «caixa» de carvão, «dando um mal jeito na paleta esquerda ${ }^{33}$. Maria reclamara à justiça que o salário informado pela empregadora na comunicação de acidente de trabalho era inferior ao que ela efetivamente recebia, como já vimos, uma prática adotada por todas companhias mineradoras do período a fim de minorar os valores das indenizações por acidentes. A Carbonífera Metropolitana enviou a seguinte tabela para se juntar aos autos:

\section{DEMONSTRACARO DE TRABALHO}

\begin{tabular}{|c|c|c|c|c|c|c|}
\hline Mezes & $\begin{array}{l}\text { Dias ou } \\
\text { horas de } \\
\text { trabalho }\end{array}$ & $\begin{array}{c}\text { Calxotes } \\
\text { de } \\
\text { escolha }\end{array}$ & Preços & $\begin{array}{l}\text { Total } \\
\text { ganho }\end{array}$ & $\begin{array}{l}\text { Yédia por } \\
\text { dia ou ho } \\
\text { ra }\end{array}$ & $\begin{array}{l}\text { Média } \\
\text { geral }\end{array}$ \\
\hline$====$ & $f===x====3$ & & & & $=E=$ & $==$ \\
\hline \multirow[t]{2}{*}{ Jane1ro } & 39 horas & & 1,80 & 70,20 & 14,00 & \\
\hline & 18 dils & 805 & 0,20 & 161,00 & 8,90 & 10,00 \\
\hline Fevereiro & 15 dias & 1.015 & 0,20 & 203,00 & 13,50 & 13,50 \\
\hline Março & 14 dias & 1.095 & 0,20 & 219,00 & 15,60 & 15,60 \\
\hline Abril & 18 dias & 1.349 & 0,20 & 269,80 & 15,00 & 15,00 \\
\hline \multirow[t]{2}{*}{ Ma10 } & 8 horas & & 1,80 & 14,40 & 14,40 & \\
\hline & 16 dias & 985 & 0,20 & 197,00 & 12,30 & 12,40 \\
\hline & 9 dias & 567 & 0,20 & 113,40 & 12,60 & 12,60 \\
\hline & & & & $T$ & & 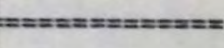 \\
\hline 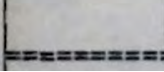 & 96 dias & 5.816 & (2) & 1247,80 & 106,30 & 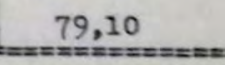 \\
\hline
\end{tabular}

Imagem 4. Processo n. ${ }^{\circ} 101$ A0818, Vara da Fazenda da Comarca de Criciúma. Fonte: Acervo Acidentes de Trabalho, CEDOC, Centro de Memória e Documentação da UNESC. Caixa 02.

O que nota-se acima é que diferente dos homens que trabalhavam no subsolo e recebiam pela quantidade de carros de carvão extraídos, o cálculo

33. Acervo Acidentes de Trabalho. Processo n. 101 A0818, Vara da Fazenda da Comarca de Criciúma. Localizado em: CEDOC, Centro de Memória e Documentação da UNESC, caixa 08. 
do salário das escolhedeiras era feito com base na quantidade de «caixotes» de escolha, e de acordo com a quantidade de horas ou dias trabalhados. Assim, o trabalho na escolha variava de acordo com o mês, como em janeiro que se trabalhou 18 dias, e em fevereiro 15 dias e março 14 dias. Isso pode ser explicável tanto pelo fato de que os acidentes na escolha eram frequentes no período, o que as obrigava a ficarem alguns dias do mês sem trabalhar; como também pelo fato de que o trabalho em casa, nas tarefas consideradas «domésticas» bem como o cuidado dos filhos ficavam todos ao seu dever, o que a consumia depois do trabalho na escolha em uma segunda jornada de trabalho.

Porém os braços e pernas das «escolhedeiras» eram extremamente necessários aos empresários do carvão por um motivo econômico: seus salários eram, geralmente, metade do pago aos homens que trabalhavam no subsolo. Fato bem observado por Boa Nova Jr. quando afirmou que: «O principal motivo (...) do emprego de mulheres nos serviços de escolha do carvão na região sul-catarinense, ao invés de homens, principalmente menores de 16 a 21 anos, é a questão de salários, pois aquelas se sujeitam a salários inferiores ao do homem $(. ..){ }^{34}$. Contudo, o argumento de que as mulheres se «sujeitavam»a salários menores ao dos homens deve ser relativizada, uma vez que a estrutura social de dominação capitalista de fábrica com vila operária, tal como se estruturou na região carbonífera de Santa Catarina em meados do século XX, impunha um padrão salarial para as mulheres inferior ao dos homens.

É importante, nesse sentido, situar o leitor sobre a configuração dessa forma de pagamento por descontos. Na literatura operária, é comum a existência de fábricas com vilas operárias. Tal como comenta em sua obra A Tecelagem dos Conflitos de Classe na Cidade das Chaminés, as fábricas que controlavam a moradia dos operários, geralmente com um aluguel descontado do salário, significava «de fato uma interferência direta e visível na administração da fábrica sobre a vida social extra-fabril dos trabalhadores» ${ }^{35}$.

Nesta outra fotografia abaixo, aparecem as casas de uma pequena Vila Operária, da Companhia Mineração Geral do Brasil, na mina «sete irmãos»:

\footnotetext{
34. Nova Jr., n. 30, p. 55-56.

35. Lopes, José Sérgio Leite. A Tecelagem dos Conflitos de Classe na cidade das Chaminés. Brasília: Ed. Marco Zero e UnB; 1988, p. 17.
} 


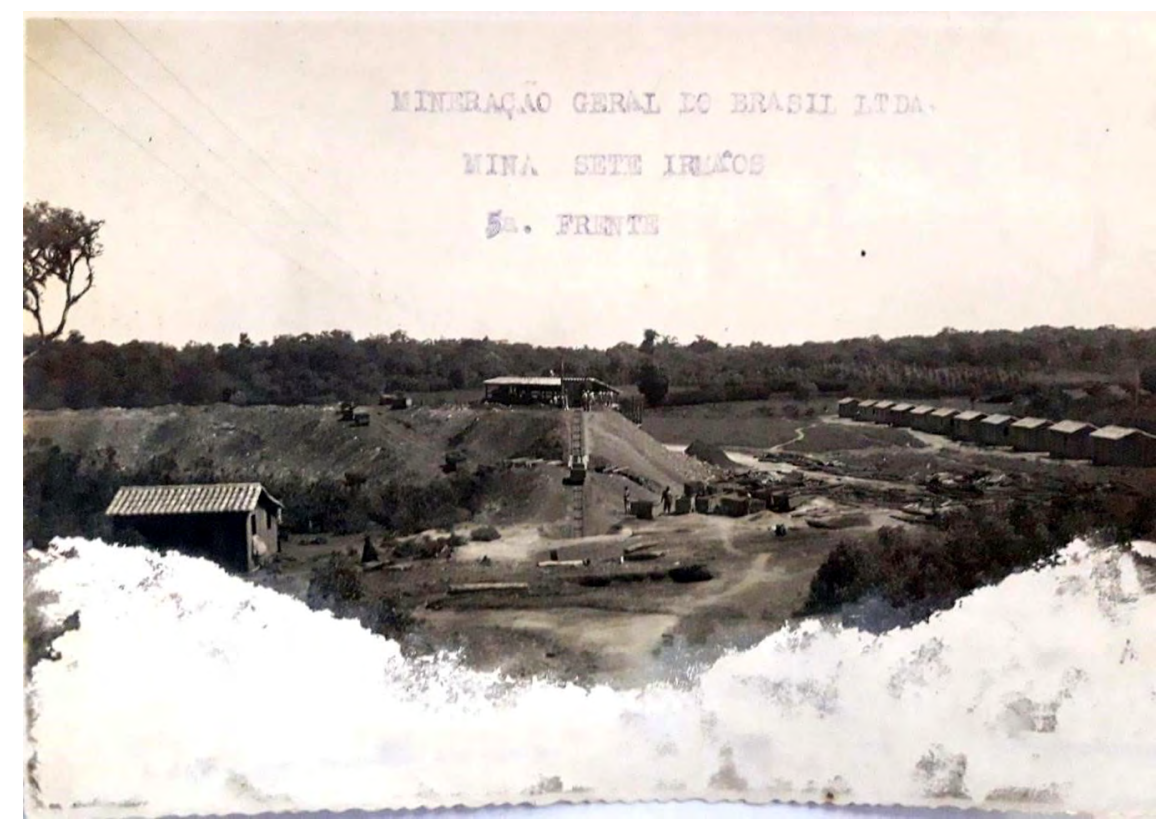

Imagem 5. Vista panorâmica da Mineração Geral do Brasil, Mina Sete Irmãos. Fonte: Acervo Arquivo Histórico Municipal Pedro Milanez.

É possível visualizar no lado direito da fotografia as casas construídas pela companhia para habitação dos operários. São somente onze casas, todas enfileiradas e próximas umas das outras. Bem próximo às casas, ao centro da foto a boca da mina, por onde entravam os trabalhadores levando suas picaretas e gasômetros nas mãos. Também por onde eram retirados os carros carregados de carvão.

A construção dessas Vilas Operárias próximas às bocas das minas demonstra que foi sendo criada uma estrutura - ainda que precária e desordenada-, de manutenção da família operária em torno das minas de carvão, de modo que elas não precisassem sair da vila para se alimentarem ou comprarem remédios, visto que as companhias carboníferas procuravam atender essas demandas, possuíam armazéns, farmácias, açougue, as casas, as fontes de água, tudo próximo às minas de carvão.

É importante salientar que a moradia nessas vilas operárias, na verdade, era descontado dos salários das trabalhadoras, que pegavam os produtos nos armazéns e farmácias de propriedade das próprias Companhias Mineradoras 
e depois tinham o valor desses produtos descontados dos salários, ao ponto de que, muitas famílias mineiras estavam sempre em dívida com as empresas.

No caso das escolhedeiras, o sistema de pagamento por descontos também funcionava assim como os homens: Carola identificou em suas entrevistas que as trabalhadoras recebiam uma ficha ou uma chapinha de alumínio de acordo com a quantidade da padiola de carvão escolhido. Com essas «chapinhas», poderia se trocar junto ao armazém da companhia por mercadorias, ou uma «ordem» (tipo de vale) para as compras, que, posteriormente, era descontada nas folhas de pagamento ${ }^{36}$.

Verificamos que esse sistema de «descontos» dos salários dos trabalhadores foi predominante ao longo do período analisado, e que os salários pagos tinham como base a produtividade, isto é, com base na quantidade extraída de carvão por carro que se pagava o salário. Através de uma pesquisa em doze processos de acidentes de trabalho, pôde-se verificar que a média salarial no período de 1943 a 1950 das escolhedeiras aumentou de Cr\$ 7,5 a Cr\$ 12,00, o que representa uma variação de $60 \%$. Mesmo assim, esse salário representava quase $1 / 4$ da média dos mineiros homens. Com o salário de uma jornada de trabalho, por exemplo, era possível a uma escolhedeira comprar $1 \mathrm{~kg}$ de carne nos açougues das companhias mineradoras, conforme tabela abaixo.

Tabela 1

Preço de produtos de primeira necessidade em Criciúma (1945-1952)

\begin{tabular}{|l|c|c|c|}
\hline \multicolumn{1}{|c|}{ Ano } & $\mathbf{1 9 4 5}$ & $\mathbf{1 9 5 1}$ & $\mathbf{1 9 5 2}$ \\
\hline Produto/Preço $(\mathrm{Cr} \$)$ & $\mathrm{Cr} \$$ & $\mathrm{Cr} \$$ & $\mathrm{Cr} \$$ \\
Açúcar $(\mathrm{kg})$ & - & 5,00 & - \\
Carne $(\mathrm{kg})$ & 7,00 & 9,60 & 12,00 \\
Banha $(\mathrm{kg})$ & - & 12,00 & - \\
Café $(\mathrm{kg})$ & 14,00 & 25,00 & 36,00 \\
Café Misturado $(\mathrm{kg})$ & - & 22,00 & - \\
Feijão $(\mathrm{kg})$ & 1,80 & 3,00 & 5,00 \\
Farinha de Mandioca $(\mathrm{kg})$ & 0,80 & 1,20 & 2,70 \\
Litro do Leite & - & - & 3,80 \\
\hline
\end{tabular}

Fontes: Lemos, Gustavo Perez. Mineiros e Sindicalistas na cidade do carvão, 1952-1964. Florianópolis: UFSC/CFH; 2008. / Milanez, Pedro. Fundamentos Históricos de Criciúma, Ed. do autor; 1991. Boa Nova Jr., Francisco de Paula. Problemas médico-sociais da indústria carbonífera catarinense. Rio de Janeiro: Departamento de Fomento da Produção Mineral; 1953.

36. Carola, n. 26, p. 31. 
Pela tabela acima, observa-se que o custo de vida se encarecia repentinamente no final da década de 1940 e começo dos anos 1950, pois entre 1951 e 1952 ocorreu variação nos preços semelhantes à ocorrida entre 1945 e 1951. Esse fato demonstra, entre outros fatores, que as doenças profissionais e acidentes laborais possuem uma estreita relação com as condições de vida e nível salarial, tal como pesquisou Óscar Gallo, sobre o médico colombiano Miguel María Calle, médico da empresa minera El Zancudo, do ramo do carvão mineral, uma das maiores da Colômbia até a primeira metade do século XX:

«Calle observo la relación entre el trabajo y las pésimas condiciones en que vivían los trabajadores debidas a los últimos acontecimientos políticos y económicos ocurridos em Colombia em la primera mitad del siglo XX. (...) Para Calle, era un problema de la pobreza. Los salarios eran absurdamente insuficientes para atender las exigencias de una familia de cinco a seis personas. (...) Afirmó que los hijos de los trabajadores estaban sometidos a influencias perniciosas, que hacían de ellos candidatos perfectos a la degeneración asténica. (...) A esto se sumaban casas estrechas, mal ventiladas, húmedas, sin agua potable, ropas insuficientes e inadecuadas» ${ }^{37}$.

Gallo comenta que questões como essas foram lançadas também pelo médico Emilio Morales (1937) que se questionava se o problema da alimentação da classe operária teria uma estreita relação com o salário-mínimo, que deveria dar ao trabalhador o poder de comprar os alimentos necessários de acordo com o esforço que o trabalho exigia ${ }^{38}$. O médico também se perguntava se a menor resistência orgânica e as enfermidades infecciosas não eram resultados da má alimentação dos trabalhadores que estavam expostos permanentemente à fadiga ${ }^{39}$.

Por suposto que esses debates sobre a fadiga da classe trabalhadora não eram fruto somente das preocupações sociais dos médicos em melhorar as condições de vida dos operários, mas também uma necessidade das indústrias em encontrar respostas para minimizar as perdas da produção resultantes da fadiga industrial e dos acidentes. Ainda de acordo com Gallo, esse hori-

37. Gallo, Óscar. Luz sobre el fenómeno de un corazón aparentemente infatigable: La fatiga de la clase obrera en Colombia, 1898-1946. In: Gallo, Óscar; Castaño, Eugenio, orgs. La salud laboral el siglo XX y el XXI: De la negación al derecho a la salud y la enfermedad. Medellín: Escuela Nacional Sindical; 2016, p. 221.

38. Gallo, n. 37, p. 228.

39. Gallo, n. 37, p. 228. 
zonte de questões lançadas pelo debate médico diziam respeito à noção de «fator humano», uma corrente de pensamento da medicina do trabalho que abarcava uma série de medidas que deveriam ser evitadas a fim de reduzir os acidentes na indústria: a falta de seleção profissional, a falta de prevenção ou racionalização de tarefas e as deficiências anatômicas ${ }^{40}$.

Essa emergente discussão travada na Colômbia na primeira metade do século XX era parte de um movimento global que se preocupava com os possíveis impactos econômicos e sociais das doenças produzidas pelo trabalho. As condições de trabalho e de vida encontrada pelo médico Miguel María Calle, assim como as informadas pela exposição das minas de carvão em França não diferiam muito das condições sociais dos mineiros das empresas da região de Criciúma em meados do século XX, conforme constatado pelas fontes pesquisadas.

Em Santa Catarina, o já citado médico Francisco de Paula Boa Nova Jr. comenta essa questão em seu relatório, no capítulo sobre a Fadiga na Indústria Carbonífera. Diz o autor que a fadiga industrial, além de fatores individuais, é fruto da existência de outros fatores: os fatores que dependem das condições de trabalho e outros, «estranhos ao trabalho», como as ocupações suplementares, a alimentação inadequada ou insuficiente, os «desregramentos da vida», o abuso do álcool, as habitações anti-higiênicas, entre outras ${ }^{41}$.

O médico sanitarista estava inserido no debate da Medicina do Trabalho que repercutia no Brasil e na América Latina em meados do século XX. De maneira geral, essa medicina estava preocupada com os efeitos nocivos da indústria moderna, principalmente no debate sobre a fadiga industrial, que apontava como solução a organização do trabalho e a prevenção dos acidentes através de uma racionalização das técnicas de trabalho e uma melhor seleção dos operários a fim de prevenir os acidentes. Além disso, Boa Nova Jr. comenta que a importância de regulamentar o trabalho pesado que exigia grande esforço físico do operário, e limitar «para cada operário ou operária, peso e volume compatíveis com sua capacidade física, regularizar-se o trabalho e estabelecer pausas necessárias ${ }^{42}$.

$\mathrm{O}$ autor do estudo reconhece que uma das principais causas dos acidentes era a fadiga dos trabalhadores que, não recebendo suficientemente

\footnotetext{
40. Gallo, n. 37, p. 238.

41. Nova Jr., n. 31, p. 65.

42. Nova Jr., n. 31, p. 64.
} 
pelo serviço que exerciam, e «em virtude de perceberem salários baixos em relação ao atual custo de vida», exercem ocupações suplementares em outras atividades após o trabalho na mina.

\section{Trabalhadoras na Justiça, uma análise dos processos de Acidentes de Trabalho}

O que pode-se relacionar com os três processos de acidentes de escolhedeiras que trouxemos nesse artigo? Como foi demonstrado ao longo deste artigo, algumas trabalhadoras entravam com ação na Justiça Comum devido aos constantes acidentes de trabalho. $\mathrm{O}$ acesso se fazia a pedido da trabalhadora, em petição ao promotor público da comarca, também denominado Curador de Acidentes pela legislação.

O número de processos, entretanto, em comparação com os processos dos trabalhadores, é muito pequeno. Do total de 458 processos de acidentes de trabalho, entre 1943 e 1950, somente 12 são de mulheres, isso representa $2,62 \%$ do total.

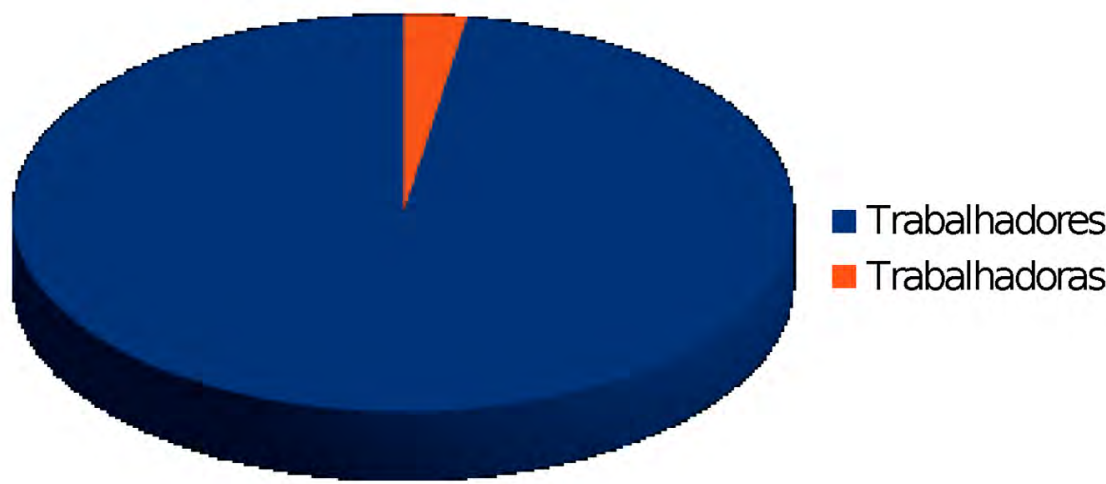

Grafo 1. Processos de Acidentes de Trabalho na mineração por sexo (1943-1950)

Desses doze processos encontrados, sete tiveram alguma demanda julgada favorável. Isso representa que $58,4 \%$ dos processos abertos por trabalhadoras, entre 1943 e 1950, tiveram alguma causa atendida no seu julgamento. Contudo, essa percentagem também representa muito pouco 
se comparado com os processos impetrados pelos trabalhadores homens: das 446 ações, somente 20 foram julgadas completamente improcedentes, e, portanto, arquivadas. Por tanto, 95,52\% das ações por acidentes impetradas por homens foram julgadas em alguma medida favorável aos trabalhadores, enquanto das mulheres este índice cai para 58,4\%.

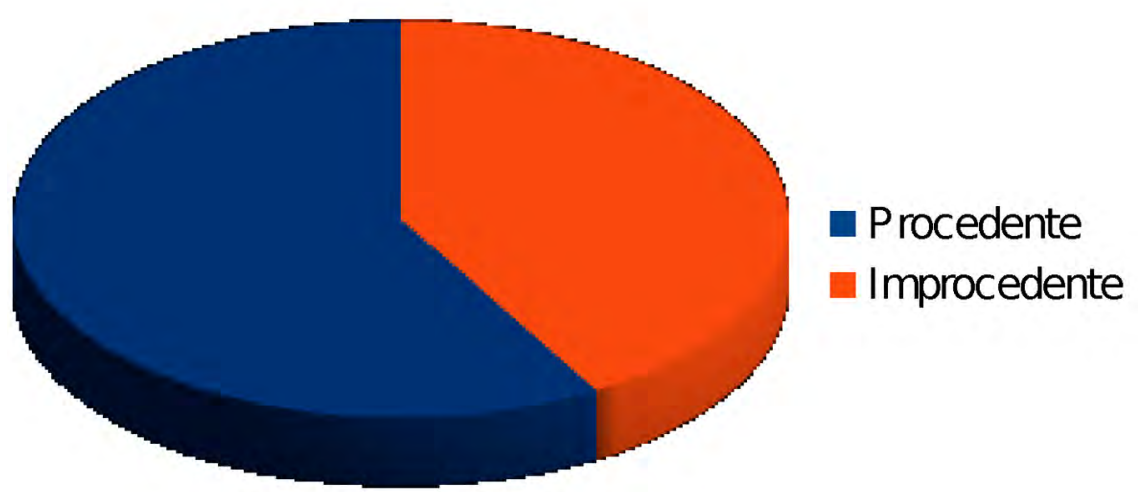

Grafo 2. Resultado dos processos impetrados por trabalhadoras (1943-1950).

Desse breve levantamento quantitativo, infere-se que era muito menor o número de processos abertos por mulheres trabalhadoras na justiça, em comparação com os homens. Embora não se dê para abrir uma generalização explicativa para todos os casos, pode-se refletir que o papel atribuído às mulheres de segundo plano na divisão sexual do trabalho no sistema capitalista contribuía para essa segregação dentro e fora dos espaços de trabalho ${ }^{43}$. Enquanto aos homens o espaço produtivo é tido como o principal, para as mulheres é considerado como secundário ou «complementar».

Portanto, a discriminação sexual na divisão do trabalho já começa na esfera produtiva, sem contudo se encerrar aí. Segundo Giulani, na sociedade brasileira, «a projeção em primeiro plano do homem trabalhador acaba deixando na sombra, quase invisíveis as péssimas condições de trabalho

43. Nogueira, Claudia Mazzei. As relações sociais de gênero no trabalho e na reprodução. Revista Aurora [artigo na Internet]. 2010 [citado 15 Out 2018]; 3 (2): 59.

Disponível em: http://www2.marilia.unesp.br/revistas/index.php/aurora/article/view/1231 
impostas às mulheres» ${ }^{44}$. Foi percebido durante a pesquisa nas fontes, que na maioria das vezes, os promotores e Juízes não davam a mesma importância social aos processos das «escolhedeiras» assim como dos mineiros. Vivendo em condições bastante precárias, sem água encanada e sem energia elétrica em suas casas, tendo que arcar com todo o serviço doméstico; e no seu trabalho, sem calçados para se protegerem dos ferimentos, sem óculos de proteção, trabalhando 8 horas por dia muitas vezes no sol, sem um espaço adequado de trabalho, as mulheres do carvão sentiam na pele a dupla jornada de trabalho. Continuando seu raciocínio, Giulani reflete que na maioria das vezes «as trabalhadoras nem são reconhecidas como parte da população economicamente ativa; sua contribuição social reduz-se ao papel de mantenedoras do equilíbrio doméstico familiar» ${ }^{45}$. Embora trate-se, evidentemente, de profissões em que a exploração do trabalho se faz de forma distinta na esfera da produção, ambas eram extremamente necessárias durante a fase de implantação da indústria carbonífera entre as décadas de 1930 e 1960.

\section{Reflexões finais}

Ao longo deste artigo buscou-se analisar quais eram as condições de trabalho e de vida das mulheres que trabalhavam na mineração de carvão no município de Criciúma, e como isso impactava em acidentes de trabalho dos mais variados tipos: desde cortes e ferimentos nos pés, pernas e mãos, relacionados a trabalharem sem equipamentos de segurança (calçados, luvas, roupas adequadas); até lesões na visão, ocasionados pelo trabalho de separação da pedra do carvão com as picaretas (a chamada escolha do carvão, feita sem o uso de óculos de proteção).

Todavia, mais do que relatar os acidentes sofridos pelas trabalhadoras, mostrou-se neste artigo que mesmo com as dificuldades encontradas no dia a dia da dupla jornada de trabalho (na mina de carvão e em casa), essas mulheres buscavam os seus direitos na Justiça, através de processos de acidentes de trabalho, quando não encontravam outra saída.

Essa ação na Justiça, prevista pela Lei de Acidentes n. 7036/1944, previa uma indenização a ser paga em virtude do acidente sofrido, caso fosse

\footnotetext{
44. Giulani, Paola Cappellin. Os movimentos de trabalhadoras e a sociedade brasileira. In: Del Priori, Mary, org. História das mulheres no Brasil-8 ed. São Paulo: Contexto; 2006, p. 641.

45. Giulani, n. 44, p. 641.
} 
comprovada a sua incapacidade parcial ou permanente. De doze processos encontrados da década de 1940, sete foram atendidos de alguma forma pela Justiça, o que representa uma taxa bem menor que os processos julgados a favor dos trabalhadores homens que ingressavam com ação na justiça. Uma das hipóteses levantadas neste artigo (que não exclui outras que porventura venham a surgir) é que a discriminação de gênero se fazia presente não só nos espaços de produção, em que o trabalho do homem (os mineiros) era considerado como principal pela sociedade da época; mas também nos espaços institucionais, como no caso da Justiça, que não permitia um amplo acesso das mulheres para pleitearem seus direitos, uma vez que de 458 ações na Justiça da década de 1940, somente 12 foram de mulheres. Entretanto, mesmo com uma estrutura social permeada de relações desiguais, as «escolhedeiras» de carvão resistiam e lutavam pela melhoria das condições de vida e de saúde. 